\title{
Parametric \& CFD Analysis of Shell and Tube Heat Exchanger by Varying Baffles Geometry
}

\author{
Abubeker Negesa Gemeda \\ School of Mechanical and Industrial Engineering, Department of mechanical engineering, Ambo University
}

\begin{abstract}
The Shell and Tube Heat Exchanger are most commonly used in current industrial production. In this study, the effect of baffle spacing on pressure drop and heat transfer coefficient are considered in a shell and tube heat exchanger with single segmental baffles and staggered tube layout. The effects of number of baffles are considered $4,6,8,10,12$, and 14 and baffle spacing are considered 366.67, 220,157.14, 122.22, 100, and 84.61 respectively with 38\% baffle cut are investigated to study the effect of pressure drop and heat transfer coefficient.Shell and tube heat exchanger with single segmental baffles is designed with same input parameters using Kern's theoretical method and Bell-Delaware method. From the CFD simulation results, heat transfer coefficient and pressure drop values for varying tube layout are provided.Variation of number of baffles with shell side pressure drop heat transfer coefficient are shown. It is discussed that for both methods (analytical calculation and CFD result) pressure drops will be increases with increases number of baffles. K- $\varepsilon$ Standard turbulence model with second order discretization and fine mesh is selected for CFD simulation considered.The result are shown highly sensitive to tube layout orientation selection, it is observed for this heat exchanger geometry $30^{\circ}$ tube layout and 14 baffle arrangement gives slightly better results.
\end{abstract}

Keywords:CFD Ansys simulation, Heat transfer coefficient, Pressure drop

DOI: $10.7176 /$ IEL/10-3-03

Publication date: November $30^{\text {th }} 2020$

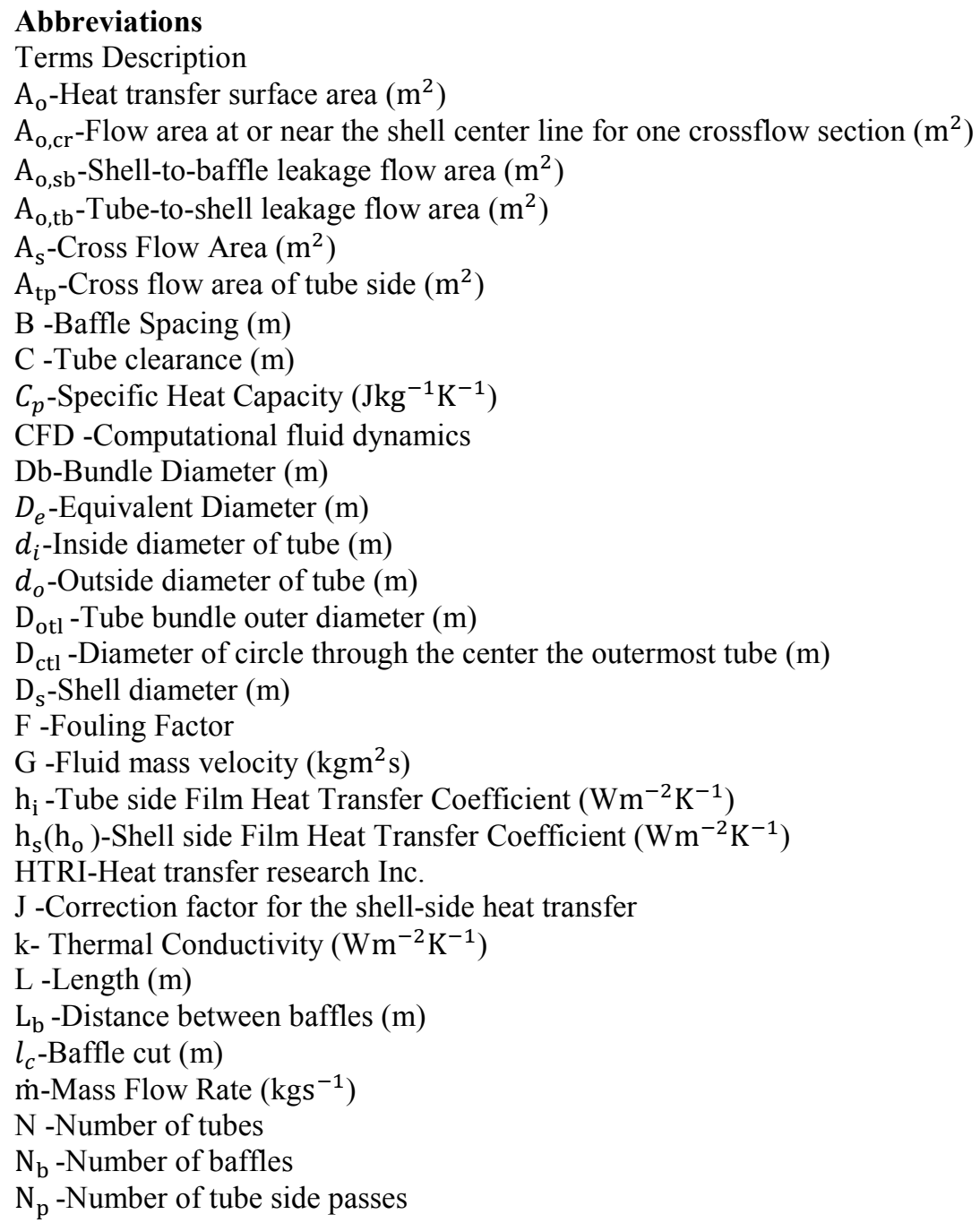


$\mathrm{N}_{\mathrm{ss}}$-Number of sealing strip pairs

$\mathrm{N}_{\mathrm{t}}$-Total number of tubes

$\mathrm{N}_{\mathrm{u}}$-Nusselt number

Pin -Pressure at inlet of the shell $(\mathrm{Pa})$

Pout -Pressure at outlet of the shell $(\mathrm{Pa})$

$\Delta \mathrm{P}$-Pressure Drop $(\mathrm{Pa})$

$\mathrm{P}_{\mathrm{r}}$-Prandtl Number

$\mathrm{P}_{\mathrm{t}}$-Tube Pitch (m)

Q -Heat Load (W)

R-Capacity Ratio

$\mathrm{R}$-Fouling resistance $\left(\mathrm{m}^{2} \mathrm{~kW}^{-2}\right)$

$\mathrm{R}_{\mathrm{e}}$-Reynolds number

S-Temperature Ratio

TEMA - Tubular exchanger manufacturers association

$\mathrm{T}_{\mathrm{ci}}$-Tube side fluid inlet temperature $\left({ }^{\circ} \mathrm{C}\right)$

$\mathrm{T}_{\text {co }}$-Tube side fluid outlet temperature $\left({ }^{\circ} \mathrm{C}\right)$

$\mathrm{T}_{\mathrm{hi}}$-Shell side fluid inlet temperature $\left({ }^{\circ} \mathrm{C}\right)$

$\mathrm{T}_{\text {ho }}$-Shell side fluid outlet temperature $\left({ }^{\circ} \mathrm{C}\right)$

$\mathrm{t}$ - Tube thickness (m)

$\mathrm{U}_{\mathrm{o}}$-Overall Heat Transfer coefficient $\left(\mathrm{Wm}^{-2} \mathrm{~K}^{-1}\right)$

$\mathrm{u}$ - Velocity $(\mathrm{m} / \mathrm{s})$

$\mathrm{X}_{\mathrm{t}}$-Transfer tube pitch $(\mathrm{m})$

$\mathrm{X}_{\mathrm{l}}$-Longitudinal tube pitch $(\mathrm{m})$

Greek Letters

$\rho$ - Density $\left(\mathrm{kgm}^{-3}\right)$

$\mu$ - Dynamic Viscosity (Pa s)

$\Delta \mathrm{T}_{\mathrm{lm}}$-Log Mean Temperature Difference

Subscript

c- Cold fluid

h- Hot fluid

i- Tube inlet

id- Ideal

o- Tube outlet

s- Shell-side

t- Tube-side

w- Tube wall

\section{Introduction}

Heat exchangers have always an important part to the lifecycle and procedure of a lot of systems. Heat exchanger is an instrument build for efficient heat transfer from one medium to another in order to bear and process energy. They usually used in petrochemical plants, chemical plants, petroleum refineries, natural gas processing, airconditioning, refrigeration, and automotive applications. Shell-and-tube heat exchangers (STHEs) are the most type of heat exchanger used in industrial processes as in nuclear power stations as condensers, steam generator in pressurized and water reactor plants, and feed water heaters. STHEs are also proposed for many others alternative energy applications as ocean thermal and geothermal ${ }^{[8]}$.

The Kern method and bell Delaware method are mostly considered for design of shell and tube heat exchanger. The result was shown Kern method is mostly used for the first round design and provides traditional results and the Bell-Delaware method was further accurate method and can give detailed results. It refers to how to predict and estimate pressure drop and heat transfer coefficient with better accuracy.

The shell and tube heat exchanger has a great variety of process and phenomena which is the amount of the material is published regarding shell and tube heat exchanger which depict different factors affecting the thermal efficiency of the shell and tube heat exchanger. Ender Ozden, IlkerTari ${ }^{[1]}$ It was studied a small shell-and-tube heat exchanger is modelled for CFD simulations. The results were used for calculating shell side heat transfer coefficient and pressure drop. These results were compared with the Kern and the Bell-Delaware results. From this study it was concluded that the simulation results are compared with the results from the Kern and BellDelaware methods by varying the baffle spacing between 6 and 12, for $0.5,1$ and $2 \mathrm{~kg} / \mathrm{s}$ shell side flow rates and the baffle cut values of $36 \%$ and $25 \%$. The results were also responsive to the baffle cut selection, for this heat exchanger geometry $25 \%$ baffle cut gives slightly improved results. Gabriel BatalhaLeoni ${ }^{[2]}$ To performed CFD simulations of a small shell and tube heat exchanger with single segmental baffles effects of baffles clearances on 
velocity, temperature and pressure profiles in the shell side flow. Geometries with and without baffle clearances was compared with CFD simulations, carried out with ANSYS Fluent 15.0. At two turbulence models were tested k-e and the SST, in order to prove their suitability to the problem. From the result SST model could capture more accurately the fluid flow characteristics close to wall regions and consequently, heat transfer effects, given that closer results to HTRI. Yusuf Ali Kara ${ }^{[5]}$ was prepared for preliminary design of shell and tube heat exchangers with single phase fluid flow both on shell and tube side a computer based design model. The program was determined to get specified heat transfer duty by calculating allowable shell side pressure drop with the overall dimension of the shell, tube bundle, and optimum heat transfer surface area. The program was covers segmental baffled U-tube, and fixed tube sheet heat exchangers one-pass and two-pass for tube-side flow. It was concluded that the allowable shell side pressure drop can be considered as a design restriction for optimum performance of shell and tube heat exchanger. The program was limited to single-segmental baffle having $25 \%$ baffle cut that was most frequently used, triangular-pitch layout that results in greatest tube density.

\subsection{Turbulence Modelling}

Turbulent flow have some characteristics properties which different from laminar flow (21)

- Turbulence is a three dimensional diffusive transport of mass, momentum and energy

- The motion of the fluid are irregular and chaotic due to random movements by the fluid

- $\quad$ The fluid has a wide range of length, velocity and time scale

- Energy has to be constantly supplied or the turbulent eddies will decay and the flow will become laminar, the kinetic energy become internal energy

\subsection{Geometry}

Heat exchanger geometry is built in the ANSYS fluent design module. It is a counter flow heat exchanger, E type shell and tube heat exchanger and the tube side is built with 19 tubes considered. One baffle cut and six baffle orientations ( $4,6,8,10,12$, and 14 number of baffles) are considered for investigation of heat exchangers and the tube of heat exchanger are arranged in triangular tube layout $\left(30^{\circ}\right)$ and square tube layout $\left(45^{\circ}\right.$ and $\left.90^{\circ}\right)$. The baffles are equally spaced.

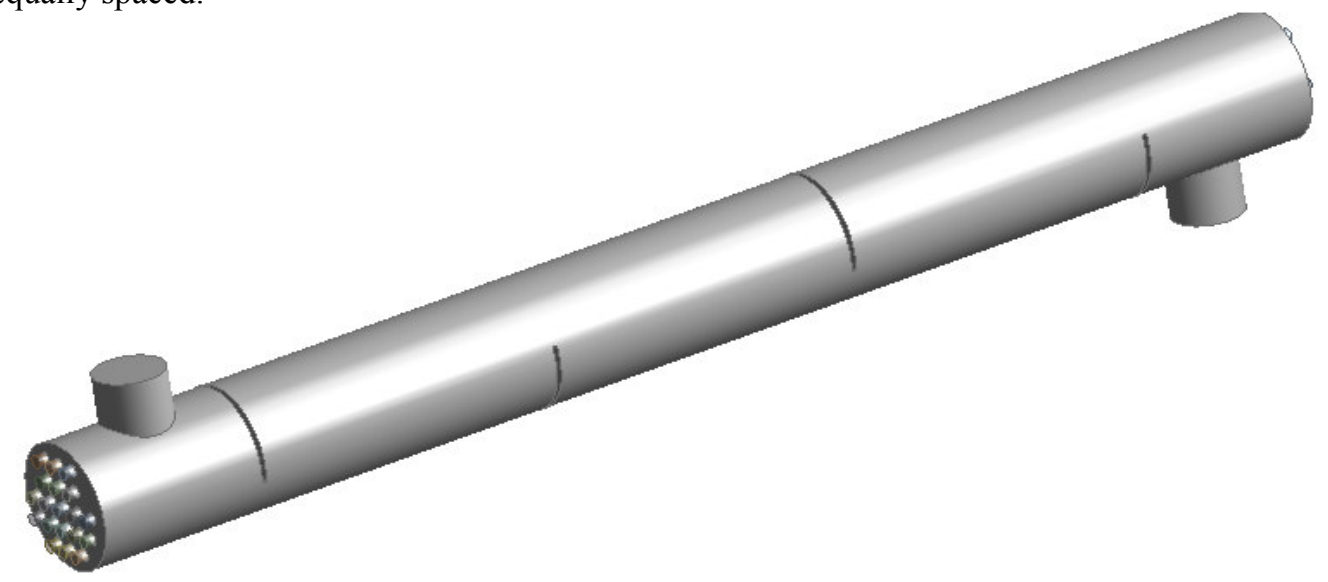

Figure1. Show schematically the shell and tube heat exchanger

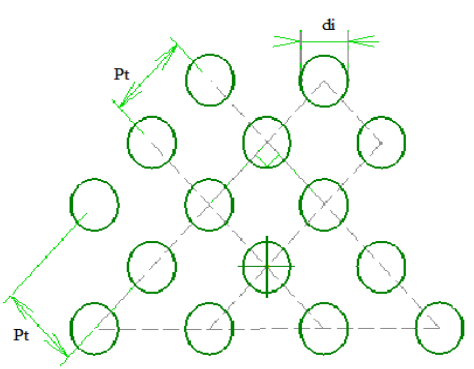

a) $45^{\circ}$ tube layout

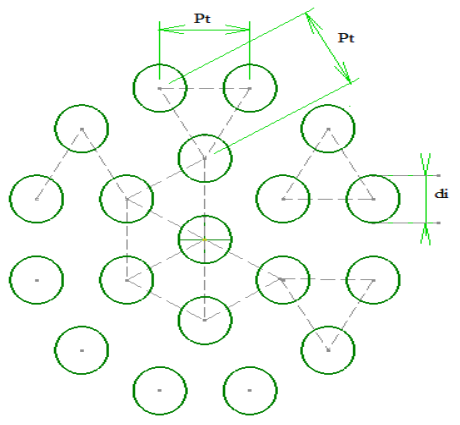

b) $30^{\circ}$ tube layout

Figure2. Tubes arrangement

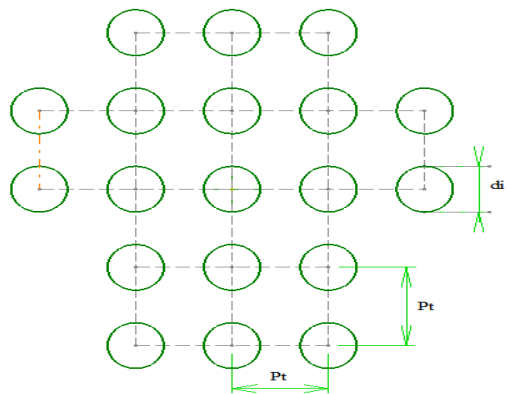

c) $90^{\circ}$ tube layout 


\subsection{Boundary condition}

For computational work to successful used a proper boundary condition. In the inlet nozzle of heat exchanger the mass flow rate and temperature values are assigned. The working fluid of the shell side is hot water, to set the shell inlet temperature is $363 \mathrm{~K}$, to assign the tube walls the constant wall temperature of $313 \mathrm{~K}$, to assign the outlet nozzle pressure is zero gauge pressure,

Table1: Boundary Conditions

\begin{tabular}{|l|l|l|l|}
\hline & BC Type & Shell & Tube \\
\hline Inlet & Inlet velocity & $1.2 \mathrm{~m} / \mathrm{s}$ & $1.6 \mathrm{~m} / \mathrm{s}$ \\
\hline Outlet & Pressure drop & 0 & 0 \\
\hline Wall & No slip condition & No heat flux & Coupled \\
\hline \multirow{2}{*}{ Turbulence } & Turbulence Intensity & $4 \%$ & $5 \%$ \\
\cline { 2 - 4 } & Length Scale & $0.005 \mathrm{~m}$ & $0.001 \mathrm{~m}$ \\
\hline Temperature & Inlet temperature & $363 \mathrm{~K}$ & $305 \mathrm{~K}$ \\
\hline Mass flow rate & & $20000 \mathrm{~kg} / \mathrm{hr}$ & $30000 \mathrm{~kg} / \mathrm{hr}$ \\
\hline
\end{tabular}

\subsection{Meshing and Grid Configuration}
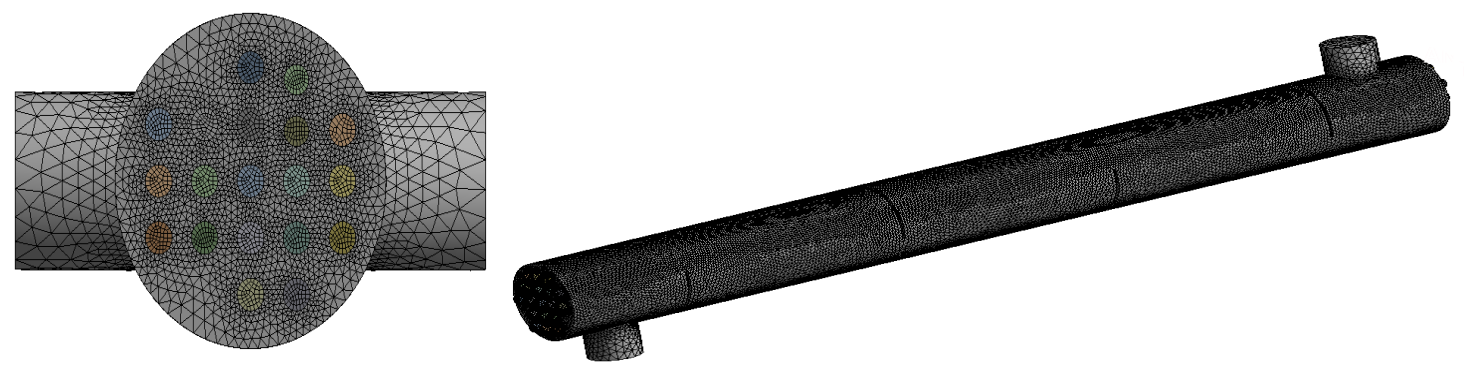

Figure 3. Typical 3D Mesh

\subsection{Result and Discussion}

As number of baffle increased the baffle spacing will be decreased. The Reynolds number in the shell side will lead to increase. That will lead to increase the overall heat transfer coefficient and at the same time pressure drop will be increased.

Table 2. Comparison of CFD Analysis and Analytical Calculation for 38\% Baffle cut

\begin{tabular}{|c|c|c|c|c|c|c|c|c|}
\hline \multirow[b]{3}{*}{$N_{b}$} & \multirow[b]{3}{*}{$\begin{array}{l}\text { Tube } \\
\text { layouts }\end{array}$} & \multirow{2}{*}{\multicolumn{2}{|c|}{ Result of CFD Analysis }} & \multicolumn{5}{|c|}{ Analytical Calculation } \\
\hline & & & & \multicolumn{2}{|c|}{ Bell-Delaware Method } & \multicolumn{3}{|c|}{ Kern Method } \\
\hline & & $\begin{array}{c}\text { Heat } \\
\text { transfer } \\
\text { coefficient } \\
\left(\mathrm{W} / \mathrm{m}^{2} . \mathrm{K}\right)\end{array}$ & $\begin{array}{c}\text { Shell } \\
\text { side } \\
\text { Pressure } \\
\text { drop } \\
(\mathrm{Pa})\end{array}$ & $\begin{array}{c}\text { Heat transfer } \\
\text { coefficient }\left(W / m^{2} . K\right)\end{array}$ & $\begin{array}{c}\text { Shell } \\
\text { side } \\
\text { Pressure } \\
\text { drop } \\
(\mathrm{Pa})\end{array}$ & & $\begin{array}{c}\text { Heat transfer } \\
\text { coefficient }\left(W / m^{2} . K\right)\end{array}$ & $\begin{array}{l}\text { Shell side } \\
\text { Pressure drop } \\
(\mathrm{Pa})\end{array}$ \\
\hline \multirow{3}{*}{4} & 30 & 3050.8 & 3230.7 & 3051.3 & 2704.4 & triangular & 3749.5 & 1189.2 \\
\hline & 45 & 3034 & 3707.6 & 3252.4 & 4132.4 & \multirow[t]{2}{*}{ square } & \multirow[t]{2}{*}{3306.3} & \multirow[t]{2}{*}{852.7} \\
\hline & 90 & 3231.6 & 3826.8 & 3283.5 & 3294 & & & \\
\hline \multirow{3}{*}{6} & 30 & 3403.2 & 5183.4 & 4171 & 4104.1 & triangular & 4965.8 & 4198 \\
\hline & 45 & 3476.8 & 6150.7 & 4427.8 & 5463.5 & \multirow[t]{2}{*}{ square } & \multirow[t]{2}{*}{4378.9} & \multirow[t]{2}{*}{3010} \\
\hline & 90 & 3699 & 5904.7 & 4473.6 & 3958.7 & & & \\
\hline \multirow{3}{*}{8} & 30 & 3786.4 & 7639.5 & 5124.88 & 5557.3 & triangular & 5975.4 & 7502.5 \\
\hline & 45 & 3900.8 & 9008.9 & 5425.7 & 7559.5 & \multirow[t]{2}{*}{ square } & \multirow[t]{2}{*}{5269} & \multirow[t]{2}{*}{7114.4} \\
\hline & 90 & 4092.5 & 9107 & 5483.7 & 5452 & & & \\
\hline \multirow{3}{*}{10} & 30 & 4248.7 & 11094.2 & 5980.8 & 8242.1 & triangular & 6861.2 & 14451.1 \\
\hline & 45 & 4379.3 & 12383.8 & 6319.6 & 10424 & \multirow[t]{2}{*}{ square } & \multirow[t]{2}{*}{6050.1} & \multirow[t]{2}{*}{13703.84} \\
\hline & 90 & 5232.7 & 12198.8 & 6388.74 & 7743.4 & & & \\
\hline \multirow[t]{3}{*}{12} & 30 & 4822.7 & 14348 & 6757.9 & 12108.1 & triangular & 7661.7 & 24558 \\
\hline & 45 & 4883.8 & 16559 & 7128.8 & 14351.6 & \multirow[t]{2}{*}{ square } & \multirow[t]{2}{*}{6756} & \multirow[t]{2}{*}{23287.6} \\
\hline & 90 & 5386.6 & 16114.7 & 7208.22 & 10979 & & & \\
\hline \multirow[t]{3}{*}{14} & 30 & 5518.4 & 20150 & 7492.44 & 17368.4 & triangular & 8399.3 & 38344.4 \\
\hline & 45 & 5424 & 21075.8 & 7893.1 & 19489.7 & \multirow[t]{2}{*}{ square } & \multirow[t]{2}{*}{7406.5} & \multirow[t]{2}{*}{36361} \\
\hline & 90 & 5526 & 21156.5 & 7982.37 & 15317.4 & & & \\
\hline
\end{tabular}


Six different numbers of baffles with $38 \%$ baffle cut are investigated to study the effect of baffle spacing on pressure drop and heat transfer. To decrease of baffle spacing, the number of baffle will increase and tube length for a given heat duty decrease. When the baffle spacing is $366.67 \mathrm{~mm}$, the number of baffles is 4 and when the baffle spacing is $84.61 \mathrm{~mm}$, the number of baffles is 14 . Variation of number of baffles and shell side pressure drop is shown in figure 4. It is observed that for both methods (analytical calculation and CFD result) pressure drops will be increases with increases number of baffles.

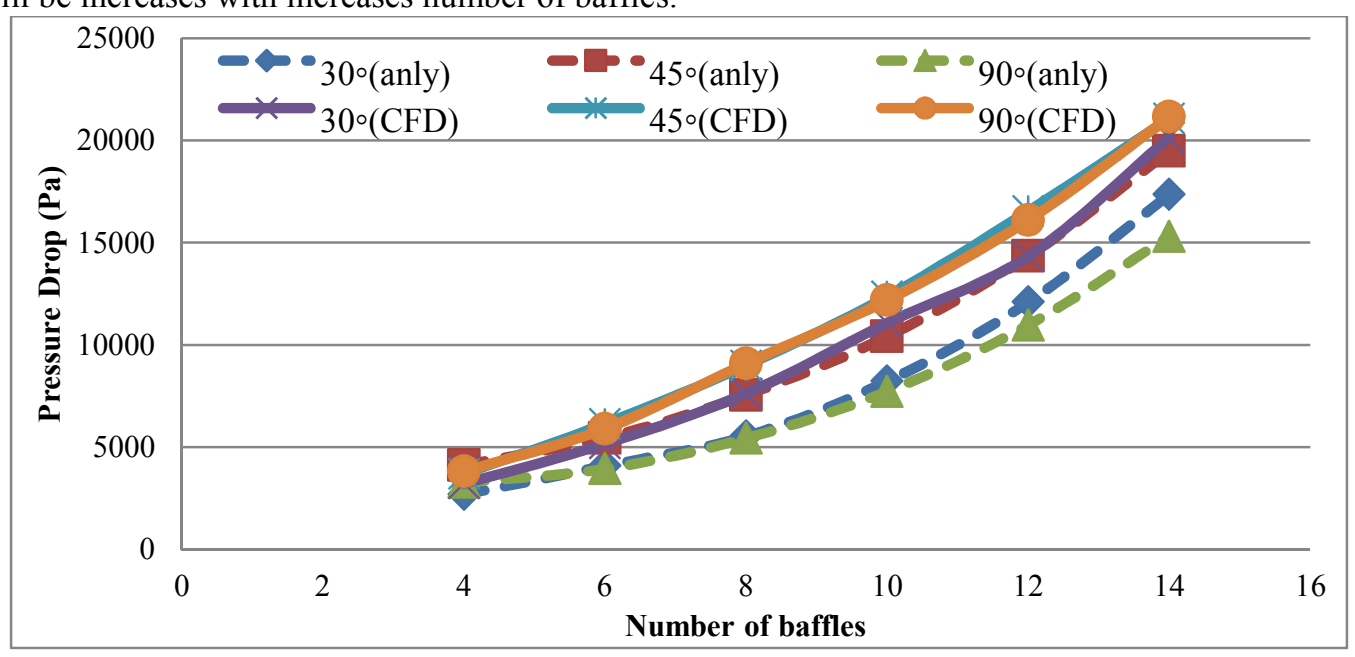

Figure 4. Number of baffles verses pressure drop

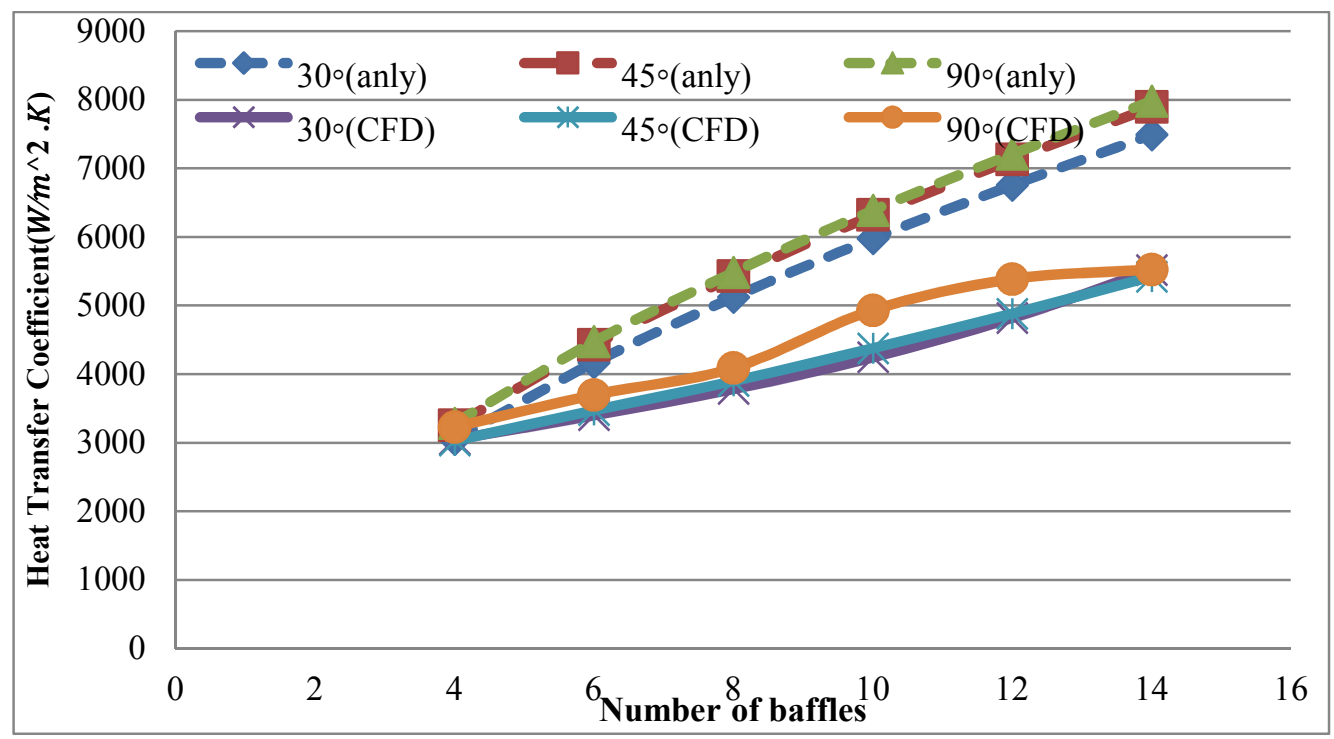

Figure 5. Number of baffle verses heat transfer coefficient

Figure 5 shows that variation of number of baffles and heat transfer coefficient. It can be establish that the heat transfer coefficient have directly relationship with number of baffles and inversely relationship with baffle spacing.

From the CFD simulation results, heat transfer coefficient and pressure drop values for varying tube layout are provided in table 2 and it is establish that the shell side heat transfer coefficient and shell side pressure drop are increasing with increasing number of baffles as expected even the variation of heat transfer coefficient is minimal as shown in Figure 5. It is establish that for three tube layout $30^{\circ}, 45^{\circ}, 90^{\circ}$ there is no much effect on outlet temperature of the shell even though the number of baffles are increased from 4 to 14 .

When Bell-Delaware results are taken as the reference value, it observed that for all $N_{b}$ values, in the case of $30^{\circ}$ the heat transfer coefficient and pressure drop are better agreements. Hence it can be noticed that shell and tube heat exchanger with $30^{\circ}$ tube layout arrangement result is reasonable pressure drop. It can be concluded shell and tube heat exchanger for these study case depending on the result the $30^{\circ}$ tube layout arrangement is better performance compared to $45^{\circ}$ and $90^{\circ}$ tube layout arrangement. 
Table 3. Baffles and its spacing

\begin{tabular}{|c|l|l|l|l|l|l|}
\hline Number of baffles $N_{b}$ & 4 & 6 & 8 & 10 & 12 & 14 \\
\hline Central baffle spacing B (mm) & 366.67 & 220 & 157.14 & 122.22 & 100 & 84.61 \\
\hline$B / D_{s}$ & 2.44 & 1.46 & 1.04 & 0.812 & 0.67 & 0.564 \\
\hline
\end{tabular}

\subsubsection{Counter plots}

As the present study, for a heat exchanger with a turbulent flow, the understanding of the result to different baffle spacing and three tube layouts are investigated with baffle cut. Variation of shell side pressure drop and heat transfer coefficient values with tube layout and baffle spacing considered.

ANSYS
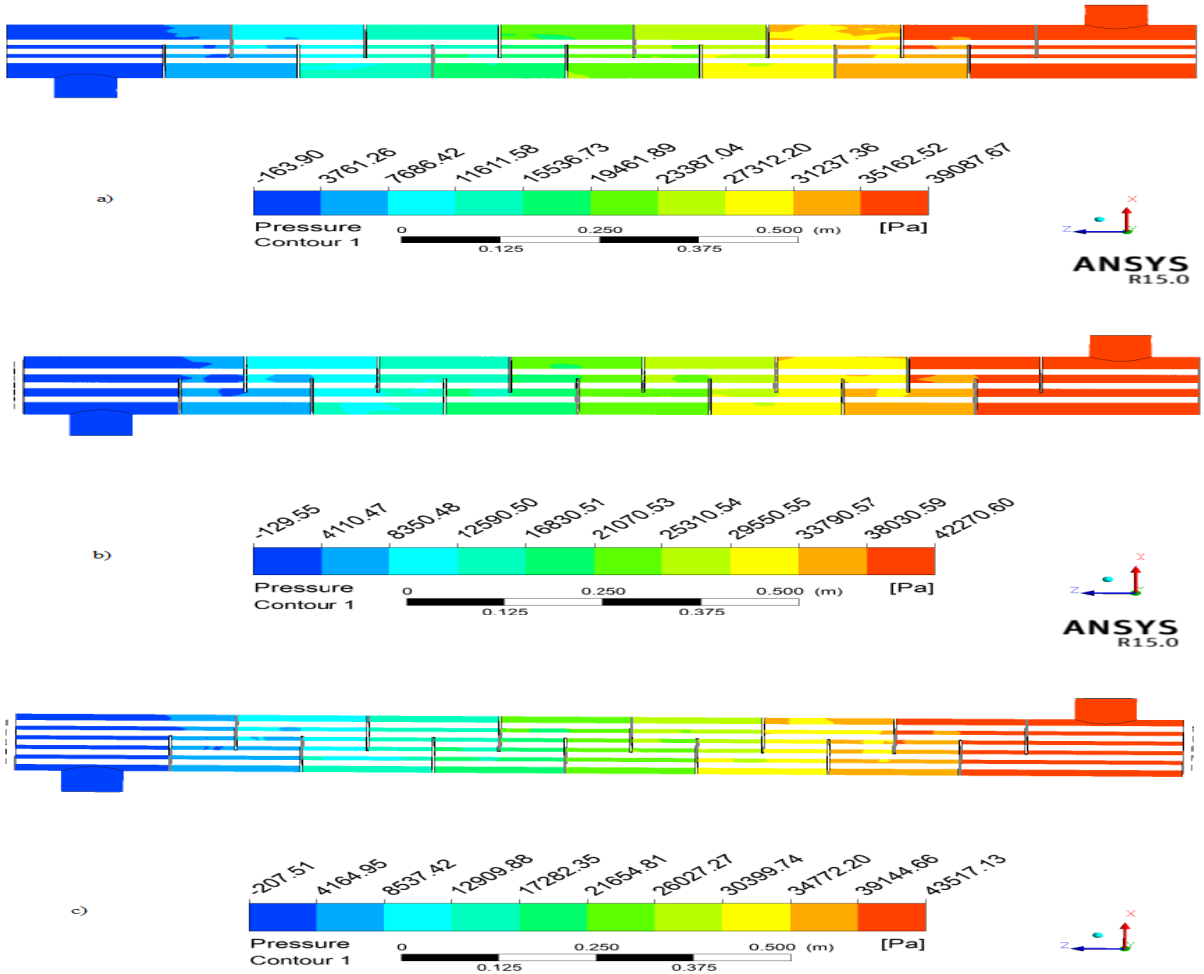

Figure 6. Pressure Counter on Shell Side When $N_{b}=14$, tube layout a) $30^{\circ}$, b) $45^{\circ}$ and c) $90^{\circ}$ 


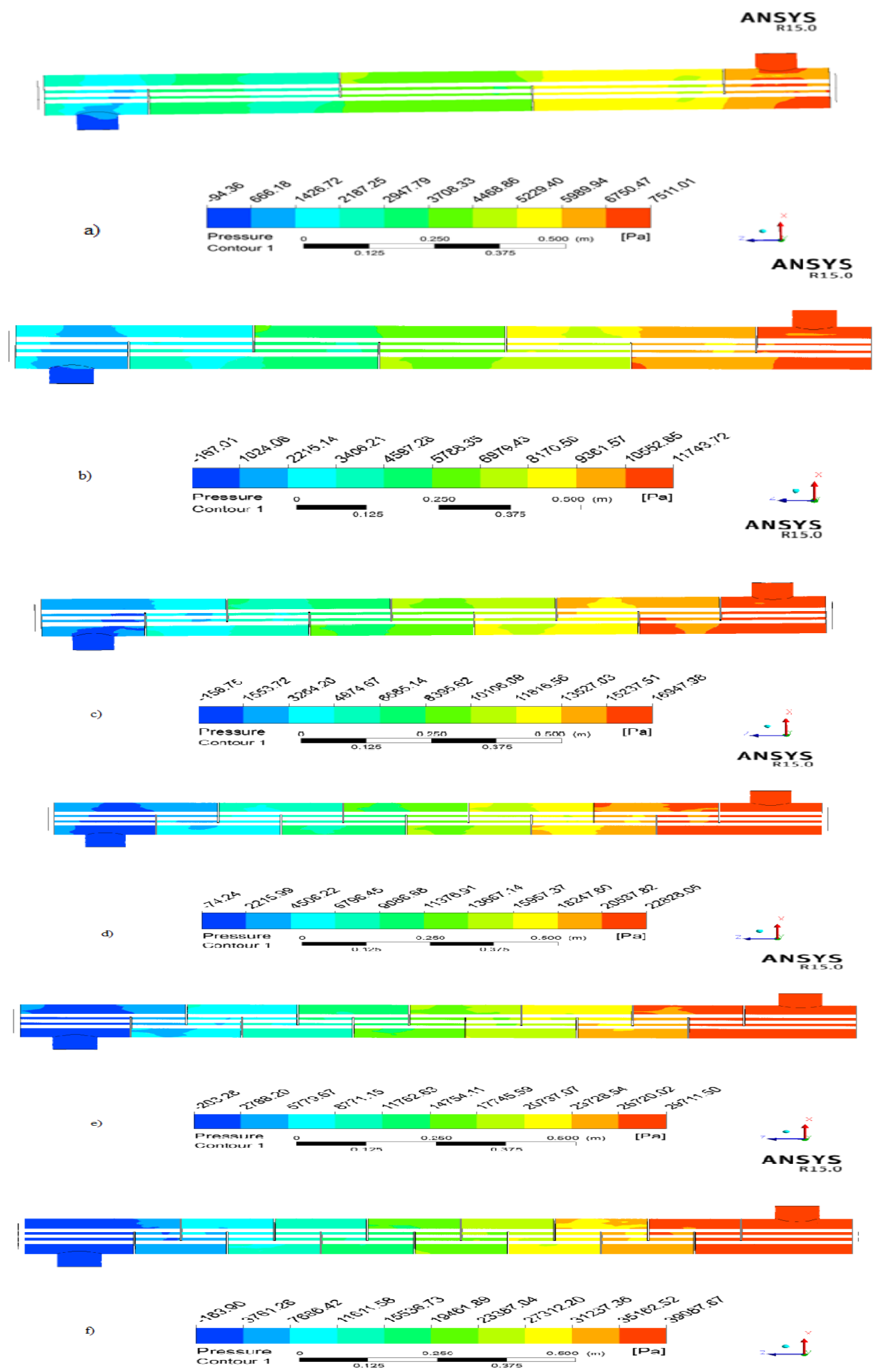

Figure 7. Pressure Drop on Shell Side When Tube Layout $=30^{\circ}$ and Number of baffles a) 4, b) 6, c) 8, d) 10, e) 12 , f) 14

Counter Temperature distributions shell side of shell and tube heat exchanger are shown in the Fig 8-9. The high heat transfer zones or where the turbulence involves the temperature of the steam reduces abruptly. This abrupt behavior is undesirable, so as the K-epsilon model shows the minimum inconsistency across the flow line. 

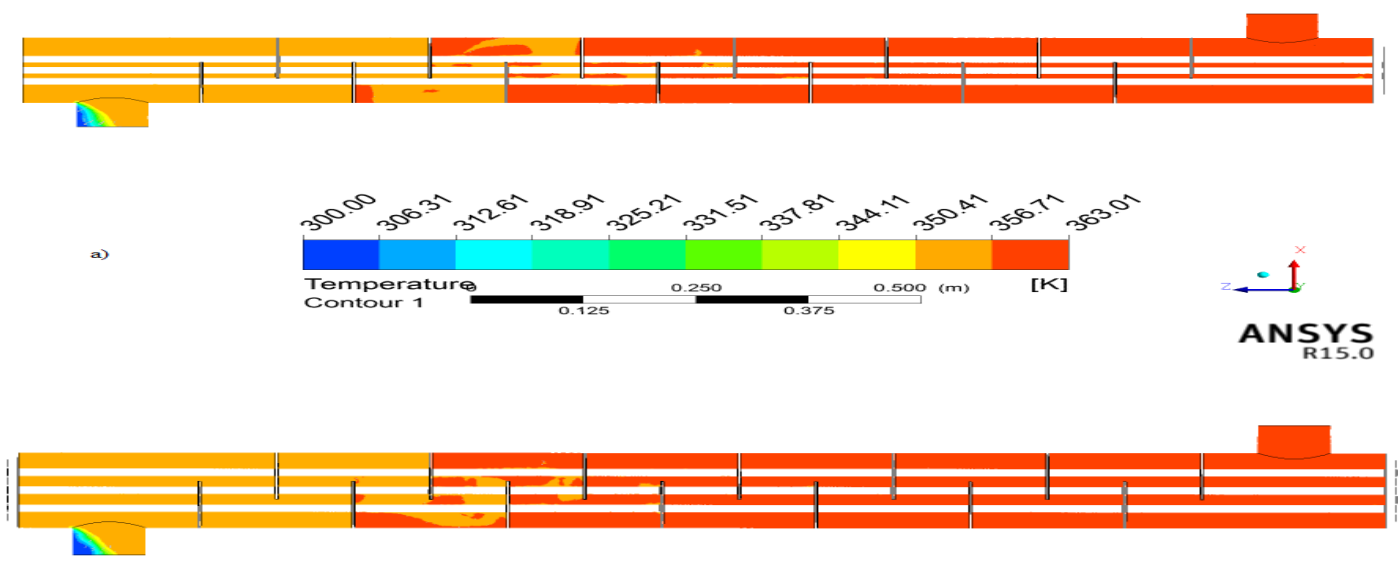

b)
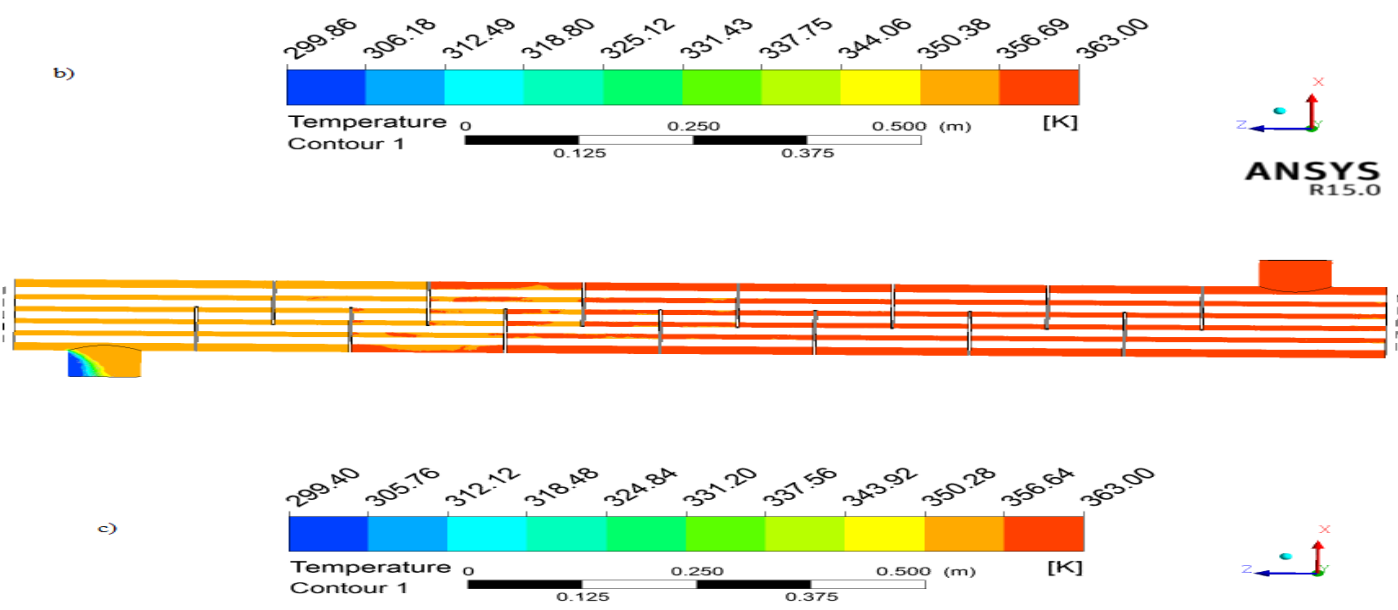

Figure 8. Temperature Counter on Shell Side When $N_{b}=14$, a) tube layout $=30^{\circ}$, b) $45^{\circ}$, c) $90^{\circ}$

ANSYS

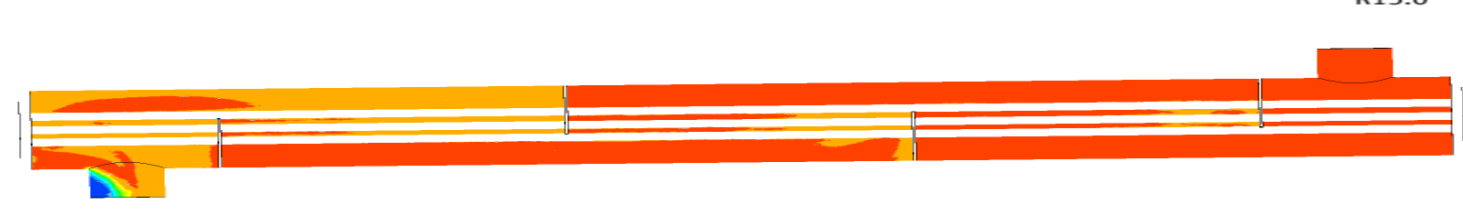

a)

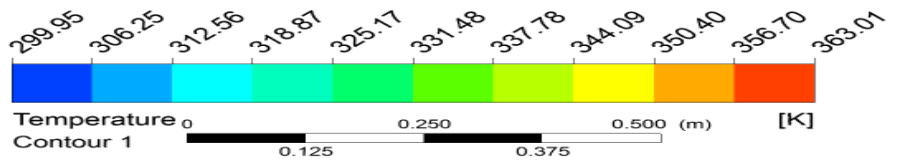




\section{ANSYS}
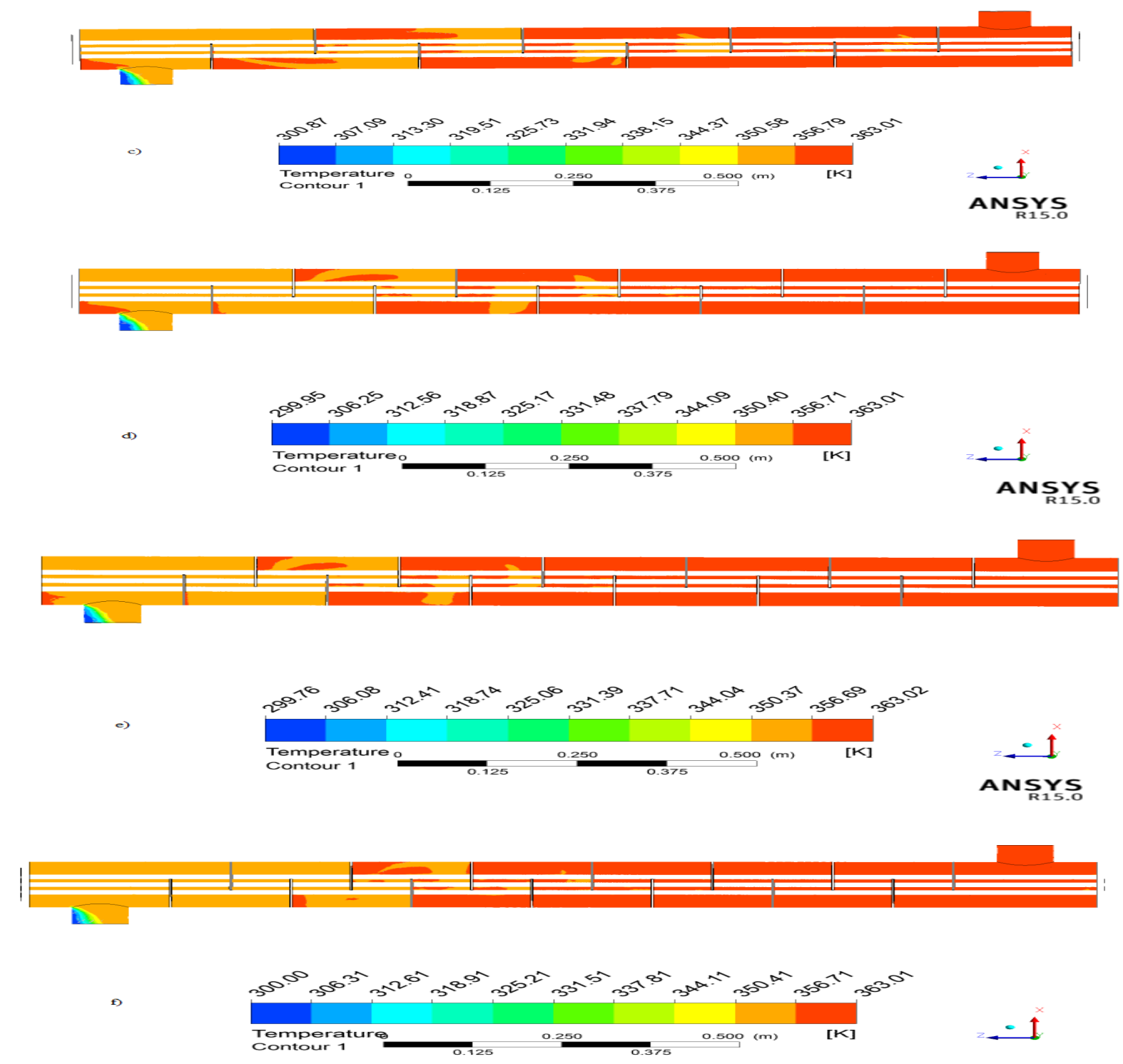

Figure 9. Temperature counter on Shell Side When Tube Layout $=30^{\circ}$ and Number of baffles a) 4, b) 6, c) 8, d) 10, e) 12, f) 14 


\subsubsection{Vector}

\section{ANSYS}
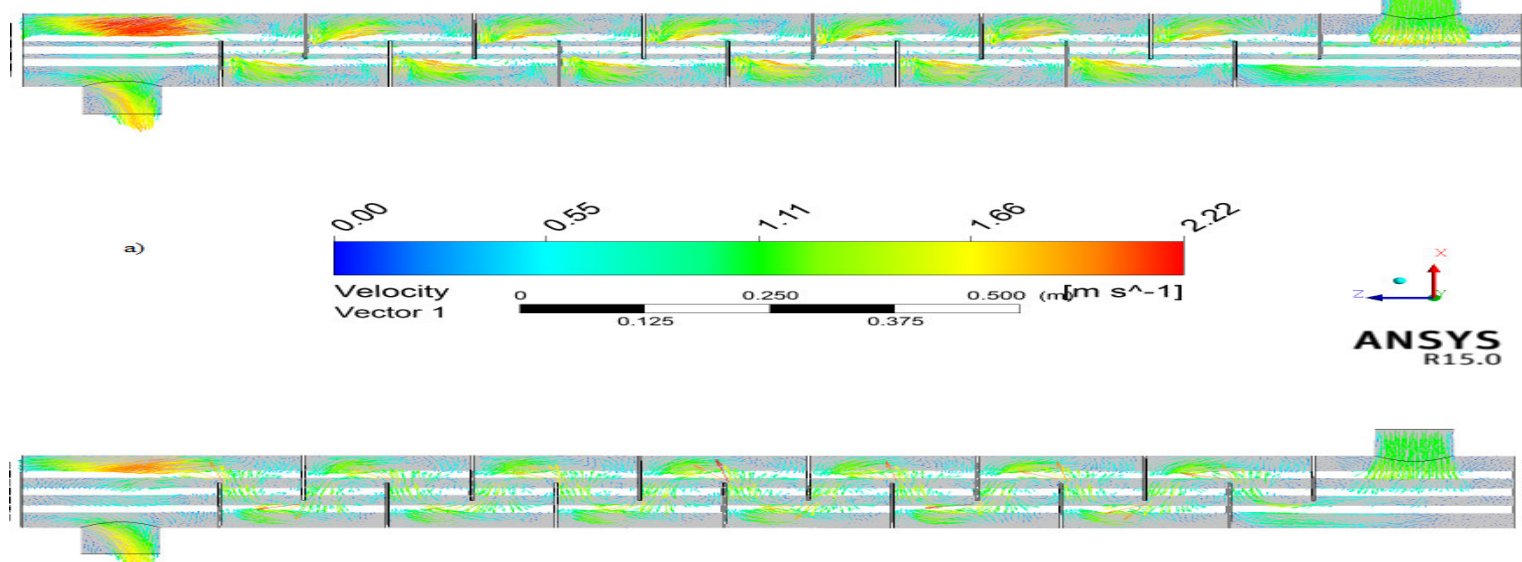

b)
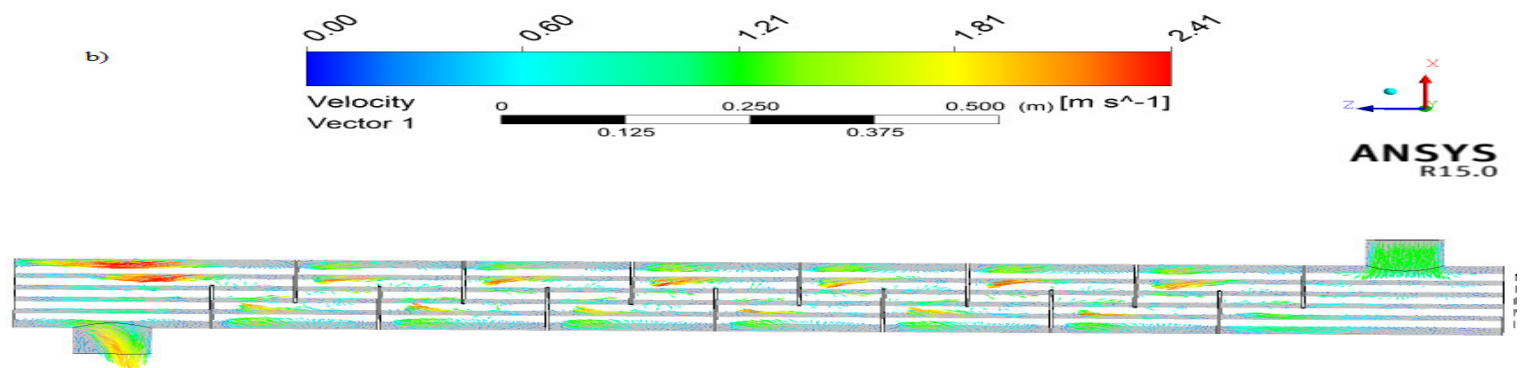

c)

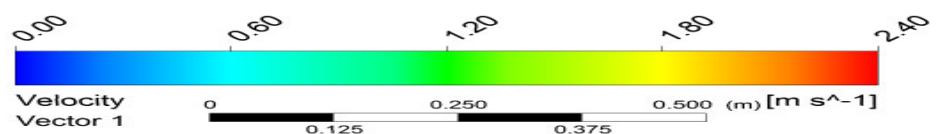

Figure 10. Velocity Vector on Shell Side When $N_{b}=14$, a) tube layout $=30^{\circ}$, b) $45^{\circ}$, c) $90^{\circ}$ 


\subsubsection{Streamline}
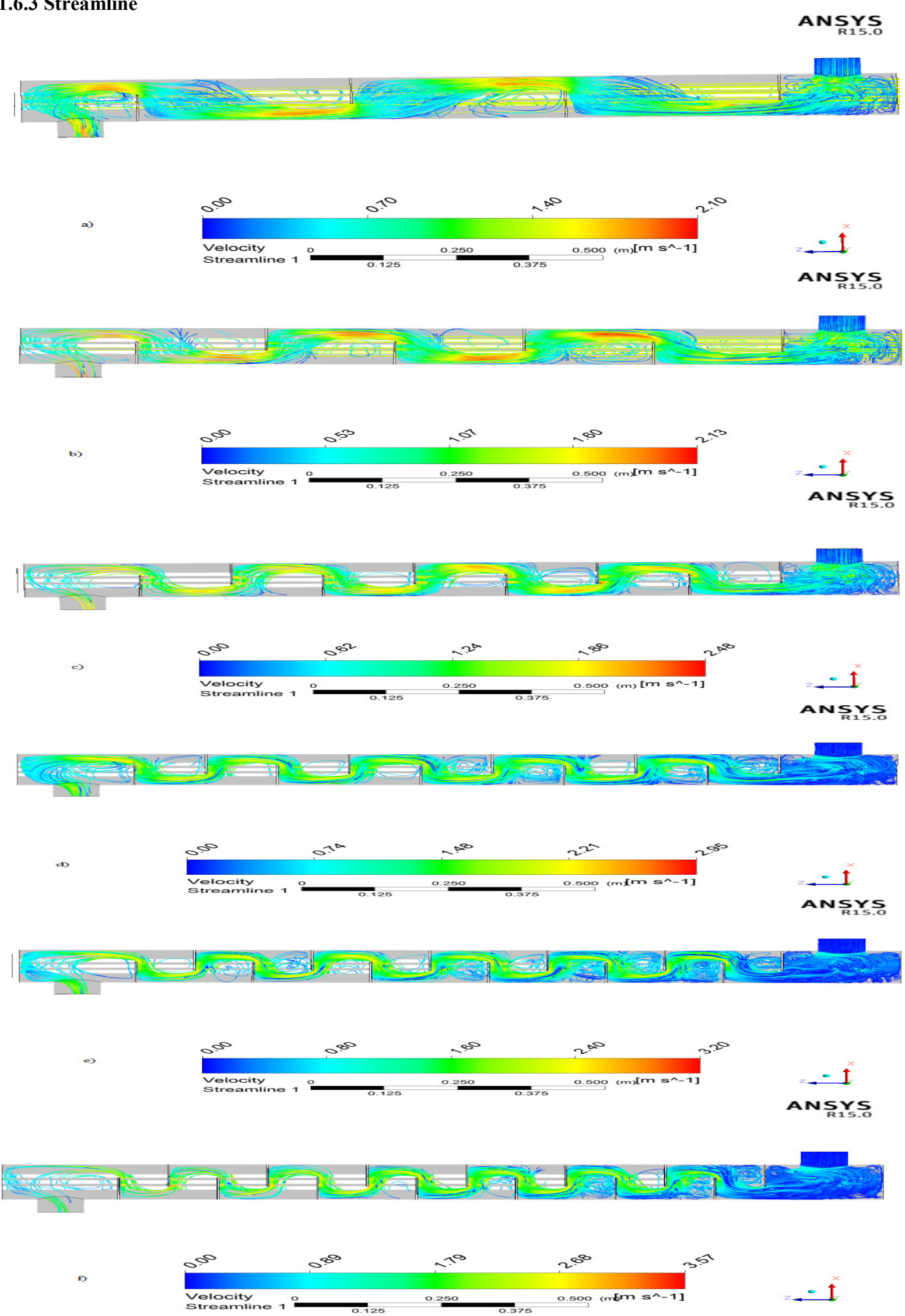

Figure 11. Velocity Streamline on Shell Side for Tube Layout $=30^{\circ}$ and Number of baffles a) 4, b) 6, c) 8, d) 10, e) $12, \mathrm{f}) 14$ 


\subsection{Conclusion}

In this study, single segmental type shell and tube heat exchanger is performed by analytical calculations which are Kern's method and Bell Delaware method and CFD analysis. Also it is discussed the pressure drop and heat transfer coefficient by varying the value of baffle spacing and tube layout arrangement with baffle cut. The thermal and dynamic characteristic in shell side of a shell and tube heat exchanger are fixed with single segmental baffle and different tube layout arrangement were numerically and CFD analysis. Six geometric configurations with different baffles spacing are recognized; which are: $366.67,220,157.14,122.22,100$, and $84.61 \mathrm{~mm}$. These values correspond to the baffle number: $4,6,8,10,12$, and 14 respectively. Effects of tube layout orientations angle $\left(30^{\circ}\right.$, $45^{\circ}$, and $90^{\circ}$ ); at baffle cut value is $38 \%$ are considered. The conclusions are summarized as follows:

$>$ The flow structure that are visualized using the CFD simulation shows that for small number of baffle, the cross flow windows are not well utilized and some recirculation zones forms behind the baffles. By increasing the number of baffles, this weakness is fixed and the heat transfer characteristics of the heat exchangers are improved.

$>$ From CFD simulation results, the shell side heat transfer coefficient and pressure drop values are obtained.

$>\mathrm{K}-\varepsilon$ Standard turbulence model with second order discretization and fine mesh is selected for CFD simulation.

$>$ The simulation result are compared with result from Kern and Bell-Delaware methods by varying number of baffles between 4 and 14 , and tube layout orientations angle are $30^{\circ}, 45^{\circ}$, and $90^{\circ}$ with $38 \%$ of baffle cut value.

$>$ It is noticed that the kern method always under predicts the heat transfer coefficient. For properly spaced baffles, it is show that the CFD simulation results are in very good agreement with the Bell-Delaware results.

$>$ The result are shown highly sensitive to tube layout orientation selection, it is observed for this heat exchanger geometry $30^{\circ}$ tube layout arrangement gives slightly better results.

$>$ The results are also sensitive to baffle spacing selection, the baffle spacing must be chosen very carefully. For this heat exchanger geometry 14 baffle gives better result.

$>$ From CFD simulation results noticed that the $30^{\circ}$ tube layout and 14 baffle are given a better heat transfer coefficient and low pressure drop. It assured that highest thermal performance is observed. This configuration is found to be the best one through my investigation and it is recommended to enhance the thermal performance of shell and tube heat exchanger.

$>$ Hence it can be concluded that shell and tube heat exchanger with $30^{\circ}$ tube layout orientation results better performance compares to $45^{\circ}$ and $90^{\circ}$ tube layout orientation and 14 baffle results give better performance compared to $4,6,8,10$, and 12 of baffles.

\section{Reference}

1. Ender Ozden, IlkerTari (2010). Shell side CFD analysis of a small shell-and-tube heat exchanger. Energy Conversion and Management. Vol. 51, No. 5, pp. 1004-1014.

2. Gabriel Batalha Leoni (2017). Assessment with computational fluid dynamics of the effects of baffle clearances on the shell side flow in a shell and tube heat exchanger. Applied Thermal Engineering. 112, 497-506.

3. Chetan Namdeo Patil N. S. Bhalkikar (2014). CFD Analysis of Shell and Tube Heat Exchanger to Study the Effect of Baffle Cut on the Pressure Drop and Heat Transfer Coefficient. International Journal for Scientific Research \& Development. Vol. 2, Issue 05, ISSN (online): 2321-0613.

4. Ali Falavand Jozaei, Alireza Baheri, Mariam K. Hafshejani and Armin Arad (2012). Optimization of Baffle Spacing on Heat Transfer, Pressure Drop and Estimated Price in a Shell-and-Tube Heat Exchanger. World Applied Sciences Journal. 18 (12): 1727-1736, ISSN 1818-4952.

5. Yusuf Ali Kara, Ozbilen Guraras (2004). A computer program for designing of Shell and tube heat exchanger. Applied Thermal Engineering. 24, 1797-1805.

6. W. Roetzel and D. Lee (1993). Experimental investigation of leakage in shell-and-tube heat exchangers with segmental baffles. Int. J. Heat Mass Transfer. Vol.3 6, No.15, pp.3765-3771

7. Rajagapal Thundil Karuppa Raj and Srikanth Ganne (2012). Shell Side Numerical Analysis of a Shell and Tube Heat Exchanger Considering the Effects of Baffle Inclination Angle on Fluid Flow. Thermal Science. Vol. 16, No. 4, pp. 1165-1174.

8. Emerson Hochsteiner de Vasconcelos Segundo (2017). Economic optimization design for shell-and-tube heat exchangers by a Tsallis differential evolution. Applied Thermal Engineering. 111, 143-151

9. S.M. Shahril, G.A. Quadir, N.A.M. Amin, Irfan Anjum Badruddin (2017). Thermo hydraulic performance analysis of a shell-and-double concentric tube heat exchanger using CFD. International Journal of Heat and Mass Transfer. 105, 781-798.

10. Andre' L.H. Costa, Eduardo M. Queiroz (2008). Design optimization of shell-and-tube heat exchangers. Applied Thermal Engineering. 28, 1798-1805. 
11. Kiran K, A M Mulla, Manoj and Umesh C J (2014). Investigation of baffle spacing effect on shell side heat transfer characteristics in shell and tube heat exchanger using computational fluid dynamics. Thermal Engg. 73, 26022-26026.

12. Kirubadurai.B, R.Rajasekaran, K.Kanagaraj, P.Selvan (2014). Heat Transfer Enhancement of Shell and Tube Heat Exchanger. International Journal for Research in Applied Science and Engineering Technology (IJRASET). Vol. 2 Issue VIII, ISSN: 2321-9653.

13. Prasanna. J, H. R. Purushothama, Devaraj K, Murugeshan (2013). A Numerical Analysis of Hydrodynamic and Heat Transfer Effects of Shell-And-Tube Heat Exchanger for Different Baffle Space and Cut. Vol. 2, No. 4, ISSN: 2320-2491.

14. Sandeep K. Patel, Professor Alkesh M. Mavani(2012). Shell \& Tube Heat Exchanger Thermal Design with Optimization of Mass Flow Rate and Baffle Spacing. International Journal of Advanced Engineering Research and Studies. Vol. II/ Issue I/130-135, E-ISSN2249-8974

15. Salim Fettaka, Jules Thibault, Yash Gupta(2013). Design of shell-and-tube heat exchangers using multi objective optimization. International Journal of Heat and Mass Transfer. 60, 343-354.

16. S. S. Shinde, P. V. Hadgekar, S. Pavithran (2012). Comparative Thermal Analysis of Helix changer With Segmental Heat Exchanger Using Bell-Delaware Method. International Journal of Advances in Engineering \& Technology. ISSN: 2231-1963.

17. Kakac S, Liu H (1997). Heat exchangers, selection, rating and thermal design. New York: CRC Press.

18. Ramesh K shah and Dusan P. Sekulic (2003). Fundamental of heat exchanger design. New York: Rochester Institute of Technology, Rochester.

19. Coulson \& Richardson's; Chemical Engineering Design. (4th Edition). Elsevier Butterworth-Heinemann. Vol.6.

20. D. Q. Kern, "Process Heat Transfer", McGraw-HillBook Company, Int. ed. 1965.

21. Korosh mohammadi (2011), PhD Thesis, Investigation of the Effects of Baffle Orientation, Baffle Cut and Fluid Viscosity on Shell Side Pressure Drop and Heat Transfer Coefficient in an E-Type Shell and Tube Heat Exchanger. Germany: University of Stuttgart. 